\title{
What are households willing to pay for improved water access? Results from a meta-analysis
}

\author{
George L. Van Houtven* ${ }^{*}$ Subhrendu K. PattanayaK ${ }^{\dagger}$ \\ FARAZ USMANI ${ }^{\ddagger} \quad$ JUI-CHEN YANG ${ }^{\S}$
}

January 4, 2017

\begin{abstract}
Although several factors contribute to low rates of access to improved water and sanitation in the developing world, it is especially important to understand and measure household demand for these services. One valuable source of information regarding demand is the growing empirical literature that has applied stated preference methods to estimate households' willingness to pay (WTP). Because it is difficult to generalize and support planning based on this scattered literature, we conduct a meta-analysis to take stock of the worldwide sample of household WTP for improved drinking water services. Using 171 WTP estimates drawn from sixty studies, we first describe this sample and then examine the potential factors that explain variation in WTP estimates. Our results suggest that households are willing to pay between approximately $\$ 3$ and $\$ 30$ per month for improvements in water access. Specifically, in line with economic theory and intuition, WTP is sensitive to scope (the size of the change in drinking water services), as well as household income, and stated-preference elicitation method. We demonstrate how our results can be used to predict household-level WTP for selected improvements in drinking water access in regions with low coverage, and find that private benefits exceed the cost of provision.
\end{abstract}

Keywords: Meta-analysis, water, sanitation, contingent valuation, willingness to pay JEL classification: Q21, Q25, Q51, Q56

*RTI International, Research Triangle Park, NC, USA. gvh@rti . org

†Corresponding author. Sanford School of Public Policy \& Global Health Institute, Duke University, Durham, NC 27708, USA. subhrendu . pattanayak@duke.edu

${ }^{\ddagger}$ Duke University, Durham, NC, USA. faraz. usmani@duke.edu

$\S$ RTI International, Research Triangle Park, NC, USA. Present address: Pacific Economic Research, LLC, Bellevue, WA, USA. yangjuichen@gmail.com

Published As: Van Houtven, G., Pattanayak, S., Usmani, F., \& Yang, J.-C. (2017). What are households willing to pay for improved water access? Results from a meta-analysis. Ecological Economics, 136, 125-135. doi:10.1016/j.ecolecon.2017.01.023

(C) 2017. This manuscript version is made available under the CC-BY-NC-ND 4.0 license. 


\section{Introduction}

For decades, the international community has recognized the widespread problems associated with inadequate water and sanitation. Yet, nearly 700 million people lack access to improved water supplies and almost 2.5 billion people lack adequate sanitation even today (WHO/UNICEF, 2015). The burden of disease imposed by inadequate water supply and sanitation services (WSS) largely falls on the developing countries of Asia, and central and southern Africa (Figure 1), and these health impacts are likely to worsen with global warming and climate change (Confalonieri et al., 2007; Haines et al., 2006). The international community initially responded to this problem by pledging to reduce the percentage of people living without basic water and sanitation services by half as part of the Millennium Development Goals (MDGs) (United Nations, 2007). A commitment to ensure universal and equitable access to safe and affordable drinking water has been upheld in the recently-adopted Sustainable Development Goals (SDGs) (United Nations, 2014). However, appraisals show that very few WSS are resilient to climate change and that the threat of climate change itself may become a major driver for improving service quality and adapting to changing conditions (Howard et al., 2010).

Unfortunately, regions that struggle with a lack of access to improved water services also face a host of other socioeconomic challenges, such as low income, energy poverty, poor education, and high rates of respiratory illness due to poor air quality. Because there are so many margins for improvement, the opportunity costs of sector-specific interventions (such as WSS delivery) can be especially high. Without a meaningful understanding of the nature and scale of the benefits of WSS, policy-makers cannot determine the optimal level of support for this sector. The planning and delivery of water and sanitation interventions must rely on economic principles of demand (Gunatilake et al., 2007; Whittington and Pattanayak, 2015). Therefore, we review and synthesize the evidence base for household demand and willingness to pay (WTP). As the global agenda refocuses on achieving the SDGs and WSS remain front and center, our analysis of household demand is timely.

Although several socioeconomic, political, and demographic factors contribute to low rates of access to WSS in the developing world, it is important to understand and measure the economic benefits associated with improved access to drinking water. One valuable source of information regarding these benefits is the extensive empirical literature that has applied stated preference (SP) methods to estimate households' WTP for improved access (Gunatilake et al., 2007). Another potential source of WTP information is from 
Figure 1: Diarrheal disability-adjusted life years (DALYs) as percentage of all-cause DALYs
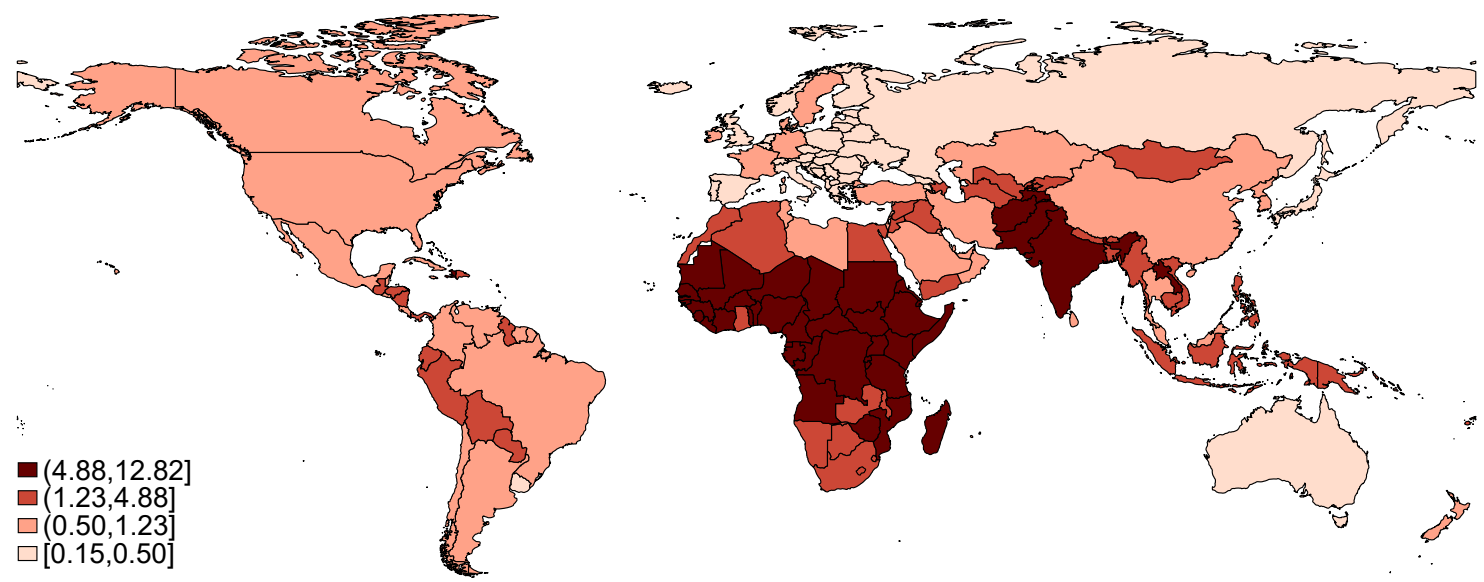

Note. This figure presents country-level diarrheal diseases DALYs as a fraction of all-cause DALYs for the year 2012. Data on DALYs obtained from the World Health Organization (2014).

revealed preferences (RP) studies on averting and preventive behaviors. However, there are at least two concerns with relying on RP studies. First, as shown by Pattanayak et al. (2010), there are simply too few RP studies from developing countries to develop any broad understanding of global demand for WSS. In addition, where there is no historical data, RP methods may not inform policies for improved supply of safe, reliable, and sufficient water in low-coverage regions. By definition, new government policies and new products are beyond the range of historical experience, setting up the case for SP studies (Whitehead et al., 2008). Second, unlike SP studies, RP studies do not provide estimates of total WTP for improved WSS because they fail to capture potentially important subcomponents of value, such as avoided pain and suffering due to illness, and nonuse values. Furthermore, concerns relating to biases in SP data can be directly examined by evaluating how study design features influence WTP estimates, e.g., multivariate regression analysis of multiple WTP estimates from multiple SP studies.

This study uses meta-analysis to first describe and then summarize results from sixty SP WTP studies conducted in different parts of the world. As prefaced, such a meta-analysis allows us to take stock of the literature on household demand for improved WSS. Metaregression analysis allows us to accomplish two other goals (Smith and Pattanayak, 2002): (1) examine a range of potential factors that explain variation in WTP estimates, including testing basic theory; and (2) predict household-level WTP for selected improvements in 
drinking water access and services. In this capacity-and, specifically, by comparing our WTP estimates to current costs of supply in different parts of the world-we comment on the prospects for implementing water and sanitation policies in line with the SDGs.

This paper proceeds as follows: Section 2 offers a brief background of meta-analysis and its application to nonmarket valuation of water and sanitation services; Section 3 presents an overview of our study-screening procedure and dataset; Section 4 describes our meta-regression models; Section 5 presents results; Section 6 presents estimates of costs and benefits of enhancing access to water services; and Section 7 concludes.

\section{Background}

Meta-analysis represents a set of methods that are now widely used to synthesize and integrate results from collections of individual studies. Although it originally evolved and has primarily been applied in the fields of health sciences and medical research, it has become increasingly popular in social science applications. In economics, the most widespread application of the meta-analytic approach is meta-regression analysis, where a common summary statistic from a set of studies investigating an empirical relationship is regressed on study-specific characteristics (such as study design or sample size) (Nelson and Kennedy, 2009). Such an exercise sheds light on what drives heterogeneity across different study sites and contexts, and is motivated in large part by the need for relatively low-cost and transferable benefit estimates to support economic analyses of a wide range of public programs and policies (Bergstrom and Taylor, 2006). Prominent applications include evaluations of gender-based wage discrimination (Stanley and Jarrell, 1998), the relationship between institutions and economic performance (Efendic et al., 2011), and the impact of environmental regulation on firms (Horváthová, 2010). Unsurprisingly, metaanalysis of nonmarket valuation and WTP studies has been a particularly active area of research (Boyle et al., 2013; Brander et al., 2006; Smith and Pattanayak, 2002; Van Houtven, 2008).

Although the empirical literature measuring households' WTP for improvements in drinking water services and access is now extensive, going back over two decades and including studies from all over the world, to our knowledge there is no peer-reviewed, published meta-analysis of this literature. ${ }^{1}$ As such, a critical need exists to take stock of

\footnotetext{
${ }^{1}$ In an unpublished Ph.D. thesis, Ukoli-Onodipe (2003) analyzed results from twenty studies on WTP for
} 
and summarize results from a large and sometimes disparate group of studies to guide our understanding of the perceived benefits of access to improved water services.

\section{Data}

Data for meta-analysis must be primarily drawn from information reported in existing studies and publications (Whitehead et al., 2008). Therefore, the first step was to identify and screen candidate studies for inclusion in the analysis. We initially identified and acquired nearly 100 potential candidate publications using Internet searches of the scholarly literature using key words such as "WTP," "willingness to pay," "contingent valuation," "sanitation," and "drinking water." Following the established protocol in the meta-analysis literature, we also used citation and reference lists linked to these studies to identify additional candidates.

As we acquired the studies, we screened them more thoroughly and selected the ones that met the following two main criteria: (1) they applied contingent valuation (CV) methods in low- or middle-income countries to measure individuals' or households' values for improved drinking water services; and (2) they reported at least one average WTP estimate for a specific sample population and defined improvement in water services. We included both peer-reviewed and "grey literature" publications to minimize publication bias.

Using information from the selected studies, we then created a database of WTP estimates. Each observation in the database corresponds to a single average WTP estimate reported in the literature. To characterize each observation, we created fields to capture the following information:

- bibliographic data for the source study/publication;

- WTP estimate, including information about the units, currency, year, frequency, and duration of payments;

- valuation method, including information about the value elicitation format;

- survey method;

- baseline drinking water conditions for survey respondents, including payments;

improved water services (including both drinking water and sanitation improvements). Although the study provides a basis for synthesizing WTP estimates, it is limited by a relatively small sample size, and does not investigate the robustness of results using alternative regression model specifications as we do. 
Figure 2: Average willingness to pay estimates for sample study countries as percentage of GDP per capita
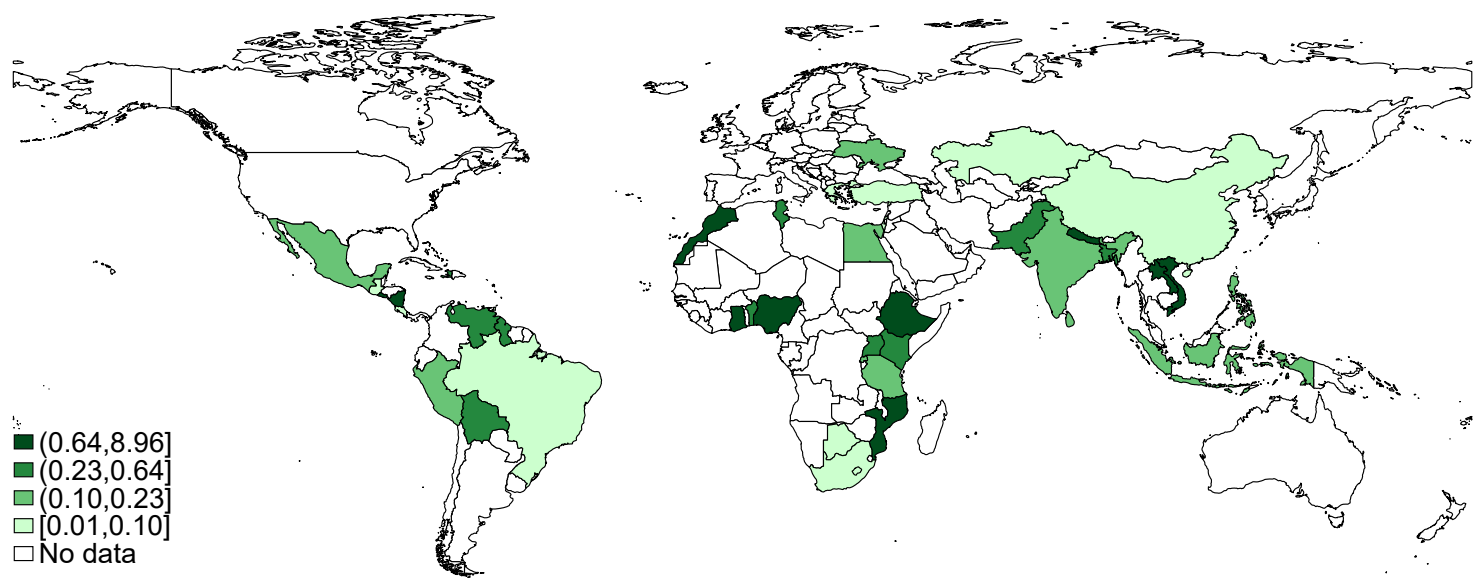

Note. This figure presents country-level averages of all willingness-to-pay estimates for improvements in water access in our sample of studies as a fraction of GDP per capita. Willingness to pay estimates are per household per month, and normalized to 2008 USD calculated at purchasing power parity (PPP). Data on 2008 GDP (PPP) per capita are obtained from the World Bank (2016).

- "commodity description," including information about each hypothetical drinking water service improvement offered to respondents, and the payment conditions;

- study location and year; and

- sample population characteristics, including average household income, household size and percentage urban/rural, and male/female.

To populate this database, WTP estimates and supporting information were highlighted in each publication and then recorded manually into a spreadsheet. To ensure the accuracy and consistency of these inputs, each data entry was individually verified and, as necessary, corrected. ${ }^{2}$

Figure 2 offers an overview of the global distribution of our sample studies and average country-level WTP estimates. The WTP database consists of 171 WTP estimates drawn from sixty valuation studies. Table 1 provides an overview of these studies. They were

\footnotetext{
${ }^{2}$ Each coded entry for each of our sample studies (i.e., the WTP estimate, corresponding sample size, baseline drinking water conditions, household income, etc.) was individually verified to confirm that the data extracted from the relevant studies had been correctly entered into our dataset. This involved independently creating two versions of our proposed dataset, and then comparing these two versions for consistency. Where inconsistencies between entries in these two preliminary versions of the dataset existed, the original study was referenced once again, and the inconsistency corrected prior to finalization.
} 
Table 1: Summary of drinking water valuation studies included in the meta-analysis

\begin{tabular}{|c|c|c|c|c|}
\hline & Publication & Country & Study Year & WTP estimates \\
\hline 1 & Aguilar and Sterner (1995) & Costa Rica & 1993 & 3 \\
\hline 2 & Akram and Olmstead (2011) & Pakistan & 2007 & 5 \\
\hline 3 & Al-Ghuraiz and Enshassi (2005) & Gaza (Israel) & 2001 & 5 \\
\hline 4 & Altaf et al. (1992) & Pakistan & 1988 & 17 \\
\hline 5 & Altaf (1994) & Pakistan & 1990 & 2 \\
\hline 6 & Arouna and Dabbert (2012) & Benin & 2007 & 1 \\
\hline 7 & Bilgic (2010) & Turkey & 2007 & 2 \\
\hline 8 & Boadu (1992) & Ghana & 1989 & 12 \\
\hline 9 & Bohm et al. (1993) & Philipinnes & 1987 & 5 \\
\hline 10 & Briscoe et al. (1990) & Brazil & 1987 & 6 \\
\hline 11 & Casey et al. (2006) & Brazil & 2001 & 4 \\
\hline 12 & Choe and Varley (1997) & India & 1995 & 2 \\
\hline 13 & Chowdhury (1999) & Bangladesh & 1998 & 4 \\
\hline 14 & Davis (2004) & Ukraine & 1996 & 4 \\
\hline 15 & del Saz-Salazar et al. (2015) & Bolivia & 2011 & 1 \\
\hline 16 & Dutta (2005) & India & 2004 & 1 \\
\hline 17 & Egziabher and Adnew (2007) & Ethiopia & 2006 & 2 \\
\hline 18 & Fissha (2006) & Ethiopia & 2006 & 2 \\
\hline 19 & Fujita et al. (2005) & Peru & 2003 & 2 \\
\hline 20 & Genius and Tsagarakis (2006) & Greece & 2004 & 1 \\
\hline 21 & Genius et al. (2008) & Greece & 2004 & 1 \\
\hline 22 & Goldblatt (1999) & South Africa & 1994 & 1 \\
\hline 23 & Gunatilake and Tachiiri (2012) & Bangladesh & 2009 & 1 \\
\hline 24 & Hoehn and Krieger (2000) & Egypt & 1995 & 2 \\
\hline 25 & Hopkins et al. (2004) & Rwanda & 2000 & 1 \\
\hline 26 & Kadisa (2013) & Botswana & 2013 & 2 \\
\hline 27 & Kaliba et al. (2003) & Tanzania & 2001 & 1 \\
\hline 28 & Kanyoka et al. (2008) & South Africa & 2005 & 3 \\
\hline 29 & Katuwal and Bohara (2007) & Nepal & 2005 & 2 \\
\hline 30 & Lauria et al. (1995) & Venezuela & 1995 & 1 \\
\hline 31 & McPhail (1993) & Morocco & 1990 & 5 \\
\hline 32 & McPhail (1994) & Tunisia & 1990 & 1 \\
\hline 33 & Nam and Son (2005) & Vietnam & 2003 & 2 \\
\hline 34 & Pattanayak et al. (2001) & Nepal & 2001 & 3 \\
\hline 35 & Pattanayak et al. (2004) & Sri Lanka & 2003 & 4 \\
\hline 36 & Perez-Pineda and Quintanilla-Armijo (2013) & El Salvador & 1999 & 1 \\
\hline 37 & Peters and Mohamed (2010) & Guyana & 2010 & 1 \\
\hline 38 & Pinheiro and Whittington (1995) & Mozambique & 1994 & 4 \\
\hline 39 & Reddy (1999) & India & 1993 & 6 \\
\hline 40 & Rosado (1998) & Brazil & 1996 & 1 \\
\hline 41 & Shah (2003) & Tanzania & 2003 & 1 \\
\hline 42 & Singh et al. (1993) & India & 1988 & 1 \\
\hline 43 & de Oca and Bateman (2006) & Mexico & 2001 & 2 \\
\hline 44 & Stoveland and Bassey (2000) & Nigeria & 1997 & 1 \\
\hline 45 & Tussupova et al. (2015) & Kazakhstan & 2012 & 4 \\
\hline 46 & Vaidya (1996) & India & 1994 & 1 \\
\hline 47 & Vásquez et al. (2009) & Mexico & 2008 & 2 \\
\hline 48 & Vásquez et al. (2012) & Nicaragua & 2009 & 1 \\
\hline 49 & Vásquez and Franceschi (2013) & Nicaragua & 2009 & 2 \\
\hline 50 & Vásquez (2014) & Guatemala & 2012 & 1 \\
\hline 51 & Virjee (2006) & Trinidad and Tobago & 2003 & 2 \\
\hline 52 & Wang et al. (2010) & China & 2006 & 1 \\
\hline 53 & Wasike and Hanley (1998) & Kenya & 1995 & 4 \\
\hline 54 & Whittington et al. (1989) & Tanzania & 1988 & 12 \\
\hline 55 & Whittington et al. (1990a) & Haiti & 1986 & 2 \\
\hline 56 & Whittington et al. (1990b) & Nigeria & 1989 & 6 \\
\hline 57 & Whittington et al. (1991) & Nigeria & 1987 & 1 \\
\hline 58 & Whittington et al. (1992) & Ghana & 1989 & 1 \\
\hline 59 & Widiyati (2011) & Indonesia & 2011 & 1 \\
\hline 60 & Wright et al. (2014) & Uganda & 2011 & 1 \\
\hline
\end{tabular}


conducted in a total of 41 different countries between 1986 and 2013. The number of WTP estimates drawn from each publication ranges from one to seventeen, with an average (median) of 2.85 (2) estimates per study. Multiple WTP estimates from a single study were only included in the database if they were (1) estimated for different changes in drinking water services, or (2) based on distinct, nonoverlapping subsamples of households (e.g., households living in separate geographic parts of the study area). If these conditions were not fulfilled, multiple estimates covering same subsample of households were either dropped or averaged into one estimate.

\section{Meta-regression models}

As mentioned earlier, using meta-regression methods, it is possible to summarize and synthesize a large number of WTP results from several studies. More importantly, it allows us to explore the sources of variation in these WTP estimates. Specifically, meta-regression can be used to address the following questions:

- To what extent is the variation in WTP estimates systematically and significantly related to observable factors?

- Do these factors affect WTP in ways that are consistent with expectations and economic theory?

If meta-regression reveals a strong systematic and consistent pattern underlying WTP estimates, then the results can also provide a useful framework for predicting average WTP under alternative conditions for planning purposes.

To establish a consistent definition for the variables expressed in monetary terms-WTP and household income-these estimates were converted to average monthly values in USD using the purchasing power parity (PPP) rate for the currency and year reported in the study. All USD values from previous years were then updated to 2008 USD using the US consumer price index (CPI). Generally speaking, the PPP is preferable to the official currency exchange rate for international price comparisons and benefit transfers because it is specifically designed to measure relative purchasing power of the currency (Pattanayak et al., 2002). ${ }^{3}$

\footnotetext{
${ }^{3}$ The meta-regression results in this application are very similar when an exchange rate conversion is used since the PPP and exchange rate are highly correlated for the years and countries included in the analysis.
} 
Table 2 describes the variables created from the WTP database and used in the metaanalysis, while Table 3 reports summary statistics for these variables. The variable WTPINCR represents the average incremental monthly WTP for improving drinking water services from baseline conditions to the service level proposed in the SP scenario. Some studies elicit and primarily report the total WTP for the final service level. For these studies, WTPINCR was constructed by deducting the baseline payment levels reported in the studies. The resulting WTPINCR variable ranges in value from $\$ 0.02$ to over $\$ 154$, with an average (median) value of $\$ 19$ (\$10.50). Partly because of its rightward skewness, we used the natural log of this variable, LNWTPINCR, as the dependent variable in our regression analyses.

The explanatory variables used in the analysis include a dummy variable (PRIVTAP) that equals one if the elicited improvement in drinking water services corresponding to each WTP estimate refers to the provision of private, in-home tap water; if, on the other hand, a particular WTP estimate has been recovered using a CV question that looks at WTP for improved public drinking water sources, its corresponding value for PRIVTAP is coded as zero.

We also include controls for households' baseline access to water services. The main objective of this to test for scope effects. If-as theory would predict-average WTP for improved drinking water services is positively related to the magnitude of the elicited water-services improvement, including these allows us to control for differences in the marginal value of service improvements associated with differences in reference conditions. Thus, three additional dummy variables (BASELINE1, BASELINE2, and BASELINE3) capture the three main levels of existing water services described in the studies, respectively: (1) unimproved drinking water source; (2) public tap; and (3) private water connection. ${ }^{4}$ Specifically, BASELINE1 equals one if the primary source of water for a majority of the sample is unimproved; BASELINE2 equals one if a majority has access to public drinking water sources; and BASELINE3 equals one if a majority has access to a private drinking water connection. Approximately 25 percent of the WTP estimates in our database are elicited from households with no access to improved water sources, 45 percent are from those with some access to a public water source, and thirty percent are from those with

\footnotetext{
${ }^{4}$ In our specifications in Table 4, we drop BASELINE1 to avoid perfect multicollinearity. Thus, the coefficients on BASELINE2 and BASELINE3 may be interpreted as the impact on average willingness to pay of households' access to public and private water sources, respectively, relative to access to only unimproved sources.
} 
Table 2: Variable descriptions

\begin{tabular}{|c|c|}
\hline Variable & Description \\
\hline WTPINCR & $\begin{array}{l}\text { Average monthly household WTP for elicited drinking water service } \\
\text { improvement (2008 PPP USD) }\end{array}$ \\
\hline LNWTPINCR & $\ln (\mathrm{WTPINCR})$ \\
\hline HHINC & Average monthly household income in sample (2008 PPP USD) \\
\hline LNHHINC & $\ln (\mathrm{HHINC})$ \\
\hline BASELINE1 & $\begin{array}{l}=1 \text { if baseline water condition for a majority of the study sample is } \\
\text { unimproved source }\end{array}$ \\
\hline BASELINE2 & $\begin{aligned}= & 1 \text { if baseline water condition for a majority of the study sample is } \\
& \text { public source }\end{aligned}$ \\
\hline BASELINE3 & $\begin{aligned}= & 1 \text { if baseline water condition for a majority of the study sample is } \\
& \text { private source }\end{aligned}$ \\
\hline PRIVTAP & $=1$ if $\mathrm{WTP}$ elicited for private connection \\
\hline HHINCMISS & $=1$ if data on average household income is missing \\
\hline URBAN & Percentage of sample that is in an urban area \\
\hline URBDUMMY & $=1$ if percentage of sample that is in an urban area $\geq 50$ \\
\hline HHSIZE & Average household size of sample \\
\hline MALE & Percentage of males in sample \\
\hline BID & $=1$ if bidding game elicitation format was used \\
\hline $\mathrm{DICH}$ & $=1$ if dichotomous choice elicitation format was used \\
\hline AFRICA & $=1$ if study was conducted in Africa \\
\hline MIDEAST & $=1$ if study was conducted in the Middle East \\
\hline AMERICA & $=1$ if study was conducted in the Americas \\
\hline ASIA & $=1$ if study was conducted in Asia \\
\hline EUROPE & $=1$ if study was conducted in Europe \\
\hline STUDYAGE & Age of the study in 2016 (years) \\
\hline PUBLISHED & $=1$ if published in a journal \\
\hline SMPLSIZE & Size of the study sample used to estimate WTP \\
\hline
\end{tabular}

Note. PPP = Purchasing power parity.

some access to a private water source (see Table 3).

A limitation of constructing the BASELINE1, BASELINE2, and BASELINE3 variables is that they do not reflect the baseline drinking water conditions for the entire sample of households in our identified studies. As such, in some instances, they may present a somewhat limited picture of actual conditions. For example, the underlying samples used to create BASELINE3 (representing some access to a private water connection by 
Table 3: Descriptive statistics

\begin{tabular}{lccccccccc}
\hline VARIABLES & MEAN & P5 & P25 & P50 & P75 & P95 & SD & MIN & MAX \\
\hline WTPINCR & 19.0 & 1.50 & 5.52 & 10.5 & 21.3 & 72.6 & 23.8 & 0.015 & 154.9 \\
LNWTPINCR & 2.35 & 0.41 & 1.71 & 2.35 & 3.06 & 4.28 & 1.19 & -4.20 & 5.04 \\
HHINC & 781.3 & 31.2 & 296.5 & 727.8 & 999.2 & 2086.1 & 680.8 & 31.2 & 3584.8 \\
LNHHINC & 6.15 & 3.44 & 5.69 & 6.59 & 6.91 & 7.64 & 1.22 & 3.44 & 8.18 \\
BASELINE1 & 0.25 & 0 & 0 & 0 & 1 & 1 & 0.44 & 0 & 1 \\
BASELINE2 & 0.45 & 0 & 0 & 0 & 1 & 1 & 0.50 & 0 & 1 \\
BASELINE3 & 0.30 & 0 & 0 & 0 & 1 & 1 & 0.46 & 0 & 1 \\
PRIVTAP & 0.74 & 0 & 0 & 1 & 1 & 1 & 0.44 & 0 & 1 \\
HHINCMISS & 0.14 & 0 & 0 & 0 & 0 & 1 & 0.35 & 0 & 1 \\
URBAN & 47.0 & 0 & 0 & 40.1 & 100 & 100 & 48.0 & 0 & 100 \\
URBDUMMY & 0.47 & 0 & 0 & 0 & 1 & 1 & 0.50 & 0 & 1 \\
HHSIZE & 6.21 & 3.90 & 4.95 & 5.89 & 7.20 & 9.50 & 1.81 & 2.90 & 12.0 \\
MALE & 0.53 & 0.29 & 0.50 & 0.50 & 0.59 & 0.75 & 0.14 & 0.051 & 0.91 \\
BID & 0.59 & 0 & 0 & 1 & 1 & 1 & 0.49 & 0 & 1 \\
DICH & 0.25 & 0 & 0 & 0 & 1 & 1 & 0.44 & 0 & 1 \\
AFRICA & 0.33 & 0 & 0 & 0 & 1 & 1 & 0.47 & 0 & 1 \\
MIDEAST & 0.088 & 0 & 0 & 0 & 0 & 1 & 0.28 & 0 & 1 \\
AMERICA & 0.18 & 0 & 0 & 0 & 0 & 1 & 0.39 & 0 & 1 \\
ASIA & 0.37 & 0 & 0 & 0 & 1 & 1 & 0.48 & 0 & 1 \\
EUROPE & 0.036 & 0 & 0 & 0 & 0 & 0 & 0.19 & 0 & 1 \\
STUDYAGE & 19.8 & 5 & 13 & 22 & 27 & 29 & 8.06 & 3 & 30 \\
PUBLISHED & 0.58 & 0 & 0 & 1 & 1 & 1 & 0.49 & 0 & 1 \\
SMPLSIZE & 284.3 & 18 & 89 & 150 & 324 & 997 & 395.4 & 2 & 3677 \\
\hline Observations & 171 & & & & & & & & \\
\hline
\end{tabular}

a majority of the sample) range from about 55 percent for a sample of households in Shoshong, Botswana as documented by Kadisa (2013), to full connectivity to a private water system for one in Matiguás, Nicaragua as documented by Vásquez et al. (2012). ${ }^{5}$ Moreover, these variables cannot fully capture differences in baseline quality-such as

\footnotetext{
${ }^{5}$ This underlying variability helps explain why a particular study may be coded as having BASELINE3 $=1$ and PRIVTAP $=0$, i.e., investigating WTP for enhancing access to public drinking water sources for households that largely have some private water access. Enhanced access to public services need not be perceived as a "reduction" in services for such communities; households facing unreliable private access, or those in communities with significant heterogeneity in access may indeed perceive benefits from improved access to alternate sources of drinking water, as we show in Table 5.
} 
water reliability, pressure, color, or taste-that may also be important determinants of the benefits that accrue to households from enhanced access (Jeuland et al., 2015; Yang et al., 2006). We note, however, that a majority of the studies we identify report multiple WTP estimates for distinct subsamples (such as households with or without a private water connection). In instances where the water access characteristics of the subsample are clearly defined, we are able to assign more accurate baseline drinking water conditions to the corresponding WTP estimate. Thus, while admittedly somewhat limited, our approach to specifying baseline drinking water conditions allows us to balance statistical power concerns with our aim of gaining new insights from the literature on demand for improved drinking water access.

Four main sample characteristic variables (HHINC, URBDUMMY, HHSIZE, and MALE) are also included as explanatory variables. ${ }^{6}$ Assuming drinking water services are a normal good, average household income is expected to have a positive effect on WTP. The mean (median) value of average monthly household income across study samples is $\$ 781$ (\$728) after 24 observations with missing data on household income are replaced with the sample mean of non-missing observations. A dummy variable (HHINCMISS) is included to account for the potential effect of these missing data. The expectations regarding HHSIZE, URBDUMMY, and MALE are less clear-cut than for household income.

Further, two CV elicitation method variables (BID and DICH) are included, with the omitted category being open-ended elicitation. ${ }^{7}$ Finally, four regional dummy variables (AFRICA, MIDEAST, ASIA, and AMERICA) and two general publication descriptors (STUDYAGE and PUBLISHED) are also included. ${ }^{8}$

\section{Results}

We summarize our meta-regression results in Table 4. We estimate the regressions using weighted least squares where each WTP data point is weighted according to the size of the underlying sample used (SMPLSIZE). In essence, this approach assumes that the

\footnotetext{
${ }^{6}$ URBDUMMY is coded as a dummy variable that equals one if at least half of the relevant subsample of households for each WTP estimate is located in an urban area (i.e., URBAN $\geq 50$ ).

${ }^{7}$ The stated preference elicitation approaches we observe in our collected studies (bidding game, dichotomous choice, and open-ended elicitation formats) map on to the stated preference nomenclature proposed by Carson and Louviere (2011)—namely, bidding game, binary/multinomial choice question, and direct question, respectively. We point readers to this work for additional insights.

${ }^{8}$ The EUROPE regional dummy variable is omitted in our meta-regression.
} 
variance of the WTP estimates is inversely proportional to the magnitude of the underlying sample sizes. ${ }^{9}$ In addition, to account for the panel structure of the data (i.e., multiple WTP estimates from individual studies), the standard errors are clustered by "study" using a Huber-White method. These are well-established methods for meta-regression analyses of WTP data (Nelson and Kennedy, 2009; Van Houtven et al., 2007).

Table 4 reports results for the full sample $(N=171)$ and for six different model specifications. Model (1) is our most parsimonious specification, only including the log of household income (LNHHINC) and a dummy variable for whether the elicited offer for the relevant estimate asks about access to a private or public source (PRIVTAP). The effect of income is positive and highly statistically significant. While the coefficient on PRIVTAP in model (1) is positive-suggesting a willingness to pay a price premium for access to a private connection-the result is not statistically significant. It is only when we control for households' baseline water access level by including the BASELINE2 and BASELINE3 dummy variables in model (2) do we see a clear, statistically significant pattern emerge. We find that households are more willing to pay for private water connections than public ones. In addition, our results strongly suggest that households' WTP for proposed improvements in water access declines as their baseline water availability improves. Thus, WTP estimates appear to be sensitive to scope; they are systematically larger for larger improvements in drinking water services.

To further examine the robustness of the regression results to model specification, in models (3)-(6) we sequentially introduce a variety of additional controls related to demographic characteristics; survey elicitation methods; global regions; and, finally, publication characteristics. Our results are consistent across all further model specifications and robust to the addition of these controls. We also find that the coefficient on the DICH dummy variable is positive and highly statistically significant in each of the specifications in which it is included. As noted by Carson et al. (2001), dichotomous choice questions attempting to elicit willingness to pay for private or quasi-public public goods face a high rate of "yes" responses since such responses increase the likelihood that the good will be provided while allowing for purchase decisions to be delayed until later, effectively enhancing the choice set at no cost. Our results are consistent with this hypothesis and prior empirical results, suggesting that dichotomous choice formats do indeed induce "yea-saying" by respondents and, thus, yield relatively high WTP values, and that open-ended formats

\footnotetext{
${ }^{9}$ Very few of the studies report variance or standard error estimates for the estimated WTP values; therefore, weighting according to sample size was used as a second-best approximation.
} 
Table 4: Willingness to pay meta-regression results

\begin{tabular}{|c|c|c|c|c|c|c|}
\hline VARIABLES & (1) & (2) & (3) & (4) & (5) & (6) \\
\hline LNHHINC & $\begin{array}{l}0.321^{* *} \\
(0.153)\end{array}$ & $\begin{array}{l}0.347^{* *} \\
(0.137)\end{array}$ & $\begin{array}{l}0.329^{* *} \\
(0.149)\end{array}$ & $\begin{array}{l}0.246^{*} \\
(0.143)\end{array}$ & $\begin{array}{l}0.248^{*} \\
(0.145)\end{array}$ & $\begin{array}{l}0.272^{*} \\
(0.157)\end{array}$ \\
\hline PRIVTAP & $\begin{array}{c}0.177 \\
(0.504)\end{array}$ & $\begin{array}{l}0.859^{* *} \\
(0.360)\end{array}$ & $\begin{array}{l}0.797^{* *} \\
(0.315)\end{array}$ & $\begin{array}{c}0.890^{* * *} \\
(0.332)\end{array}$ & $\begin{array}{l}0.886^{* *} \\
(0.338)\end{array}$ & $\begin{array}{l}0.949^{* *} \\
(0.363)\end{array}$ \\
\hline BASELINE2 & & $\begin{array}{c}-1.133^{* * *} \\
(0.324)\end{array}$ & $\begin{array}{c}-0.971^{* * *} \\
(0.327)\end{array}$ & $\begin{array}{c}-1.088^{* * *} \\
(0.339)\end{array}$ & $\begin{array}{c}-1.075^{* * *} \\
(0.356)\end{array}$ & $\begin{array}{c}-1.118^{* * *} \\
(0.341)\end{array}$ \\
\hline BASELINE3 & & $\begin{array}{c}-1.418^{* * *} \\
(0.337)\end{array}$ & $\begin{array}{c}-1.315^{* * *} \\
(0.347)\end{array}$ & $\begin{array}{c}-1.384^{* * *} \\
(0.399)\end{array}$ & $\begin{array}{c}-1.397^{* * *} \\
(0.435)\end{array}$ & $\begin{array}{c}-1.455^{* * *} \\
(0.441)\end{array}$ \\
\hline HHINCMISS & & & $\begin{array}{l}-0.168 \\
(0.388)\end{array}$ & $\begin{array}{c}0.205 \\
(0.307)\end{array}$ & $\begin{array}{c}0.196 \\
(0.322)\end{array}$ & $\begin{array}{c}0.156 \\
(0.343)\end{array}$ \\
\hline URBDUMMY & & & $\begin{array}{c}0.328 \\
(0.228)\end{array}$ & $\begin{array}{c}0.209 \\
(0.265)\end{array}$ & $\begin{array}{c}0.251 \\
(0.249)\end{array}$ & $\begin{array}{c}0.116 \\
(0.236)\end{array}$ \\
\hline HHSIZE & & & $\begin{array}{c}0.0478 \\
(0.0710)\end{array}$ & $\begin{array}{c}0.0637 \\
(0.0690)\end{array}$ & $\begin{array}{c}0.0696 \\
(0.0764)\end{array}$ & $\begin{array}{c}0.0732 \\
(0.0780)\end{array}$ \\
\hline MALE & & & $\begin{array}{l}-0.390 \\
(0.793)\end{array}$ & $\begin{array}{l}-0.168 \\
(0.822)\end{array}$ & $\begin{array}{c}0.256 \\
(0.907)\end{array}$ & $\begin{array}{c}0.315 \\
(1.114)\end{array}$ \\
\hline BID & & & & $\begin{array}{c}0.450 \\
(0.422)\end{array}$ & $\begin{array}{c}0.440 \\
(0.424)\end{array}$ & $\begin{array}{c}0.605 \\
(0.414)\end{array}$ \\
\hline $\mathrm{DICH}$ & & & & $\begin{array}{c}0.933^{* * *} \\
(0.310)\end{array}$ & $\begin{array}{c}0.931^{* * *} \\
(0.323)\end{array}$ & $\begin{array}{c}0.965^{* * *} \\
(0.334)\end{array}$ \\
\hline AFRICA & & & & & $\begin{array}{l}-0.0541 \\
(0.531)\end{array}$ & $\begin{array}{c}-0.262 \\
(0.549)\end{array}$ \\
\hline MIDEAST & & & & & $\begin{array}{l}-0.131 \\
(0.425)\end{array}$ & $\begin{array}{l}-0.213 \\
(0.495)\end{array}$ \\
\hline AMERICA & & & & & $\begin{array}{c}0.164 \\
(0.453)\end{array}$ & $\begin{array}{c}-0.0399 \\
(0.499)\end{array}$ \\
\hline ASIA & & & & & $\begin{array}{l}-0.154 \\
(0.546)\end{array}$ & $\begin{array}{l}-0.418 \\
(0.587)\end{array}$ \\
\hline STUDYAGE & & & & & & $\begin{array}{c}-0.0214 \\
(0.0208)\end{array}$ \\
\hline PUBLISHED & & & & & & $\begin{array}{l}-0.184 \\
(0.269)\end{array}$ \\
\hline Constant & $\begin{array}{c}0.332 \\
(0.934)\end{array}$ & $\begin{array}{c}0.679 \\
(0.773)\end{array}$ & $\begin{array}{c}0.454 \\
(1.075)\end{array}$ & $\begin{array}{c}0.237 \\
(1.114)\end{array}$ & $\begin{array}{c}-0.00566 \\
(1.299)\end{array}$ & $\begin{array}{c}0.461 \\
(1.202)\end{array}$ \\
\hline Observations & 171 & 171 & 171 & 171 & 171 & 171 \\
\hline R-squared & 0.084 & 0.219 & 0.240 & 0.310 & 0.318 & 0.332 \\
\hline
\end{tabular}

Note. This table presents weighted least squares regression results for the full sample of willingness to pay (WTP) estimates; each estimate is weighted by its underlying sample size. The dependent variable for each model is LNWTPINCR. Standard errors are clustered at the study level and shown in parentheses. ${ }^{* * *} p<0.01$, ${ }^{* *} p<0.05,{ }^{*} p<0.1$ 
induce respondents to understate their true maximum WTP (Carson, 2000; Holmes and Kramer, 1995).

We find no statistically significant differences in WTP across regions per se (that is, controlling for other socio-demographics that differentiate the regions). The estimated effect of household size is positive but also not statistically significant. Nevertheless, when evaluated at the mean value of the household size variable, the magnitude of the coefficient estimates suggests that WTP increases roughly in proportion to household size.

\section{So what? Costs and (model-predicted) benefits of plans to im- prove drinking water supply}

Beyond synthesizing results and testing hypotheses related to WTP estimates, the metaregression functions in Table 4 provide models that can be used to predict WTP for alternative conditions and changes. We illustrate this application of the meta-regressions in Table 5, which uses the sixth model specification from Table 4 to predict average monthly household WTP for different combinations of BASELINE1, BASELINE2, BASELINE3, and PRIVTAP. ${ }^{10}$ For all of these predictions, the other explanatory variables in the model are set at their sample mean values (see Table 3). The predicted WTP values range from approximately $\$ 3$ per month (with a ninety percent confidence interval of $\$ 1.1$ to $\$ 6.1$ ) to $\$ 33.5$ per month ( $\$ 17.9$ to $\$ 66.0$ ). As expected, larger improvements in drinking water access and services (i.e., private connections versus public sources) lead to higher predicted WTP values, and higher baseline levels have the opposite effect. To avoid the assumptions regarding baselines and to obtain general estimates for WTP, we can use model (1) in Table 4, which does not specify BASELINE2 and BASELINE3 as explanatory variables, to also predict monthly household WTP. These values range from $\$ 9.2$ (\$3.4 to \$16.1) for access to public water sources to $\$ 11$ ( $\$ 8.8$ to $\$ 15.4$ ) for access to private water services. As expected these estimates fall in the mid-range of the values in Table 5.

Next, we wish to demonstrate how predictions of household WTP, one of the two goals of meta-analysis (Smith and Pattanayak, 2002), could allow policy-makers to target WSS delivery, for example, by mapping spatial heterogeneity in demand. Using estimates from model (1) of Table 4, we calculate household-level WTP for private water sources

\footnotetext{
${ }^{10}$ To appropriately transform the model prediction of mean $\ln (\mathrm{WTP})$ to mean WTP, we applied a smearing factor to the exponentiated model predictions of LNWTPINCR (Duan, 1983). This factor is equal to the average of the exponentiated residuals for the 171 observations in the estimation sample.
} 
Table 5: Predicted mean willingness to pay for selected drinking water improvements by baseline water access conditions, USD per household per month

\begin{tabular}{ccccc}
\hline & & \multicolumn{3}{c}{ Baseline drinking water conditions } \\
& & BASELINE1 & BASELINE2 & BASELINE3 \\
\hline \multirow{2}{*}{$\begin{array}{c}\text { Elicited drinking water } \\
\text { improvement }\end{array}$} & PRIVTAP = 1 & 33.5 & 11.0 & 7.8 \\
& & $(17.9,66.0)$ & $(7.8,17.2)$ & $(5.2,12.8)$ \\
& PRIVTAP = 0 & 13.0 & 4.2 & 3.0 \\
& & $(5.2,20.9)$ & $(1.8,7.7)$ & $(1.1,6.1)$ \\
\hline
\end{tabular}

Note. This table presents predicted estimates of mean willingness to pay for enhancement in private (PRIVTAP $=1$ ) and public (PRIVTAP $=0$ ) drinking water services dependent on baseline drinking water conditions (BASELINE1, BASELINE2, and BASELINE3). These estimates are based on the regression results presented in model (6) of Table 4 and are in 2008 USD calculated at purchasing power parity. Bootstrapped 90 percent confidence intervals are shown in parentheses.

for all countries (see Figure 3, panel $a$ ). As these estimates may mask considerable withincountry heterogeneity, we also repeat this exercise for subnational jurisdictions across India and Tanzania (Figure 3, panels $b$ and $c$ ). ${ }^{11}$ While these estimates are derived from a few parameters (which themselves are estimated from 171 WTP estimates) and therefore are imprecise (point estimates are noisy, compared to estimates of means), the exercise nevertheless demonstrates two features of WSS demand. WTP for access to improved water services is high (1) in countries with relatively high burden of disease related to lack of water access, and (2) where the financial viability of investments in water infrastructure is a key concern.

Planning could further improve by comparing such benefits to costs. Thus, as a final illustration of the meta-analytic model's tractability, we also compare the WTP predictions from the model with international cost estimates for expanding access to improved drinking water services. Haller et al. (2007) estimate the region-specific per capita costs of specific interventions for improving access to safe drinking water supplies and adequate sanitation services. One intervention would increase overall coverage for improved services to 98 percent in each region in 2000, and another would increase coverage for piped water and sewage connections to 98 percent.

Valid comparisons of these costs to the WTP predictions from our meta-analytic regres-

\footnotetext{
${ }^{11}$ The choice of these two countries is partly motivated by the availability of high quality subnational income statistics: gross state domestic product from the World Bank (2013) for India, and regional gross domestic product from Tanzania's National Bureau of Statistics (2014).
} 
Figure 3: Willingness to pay for private water access, USD per household per month

(a) Global

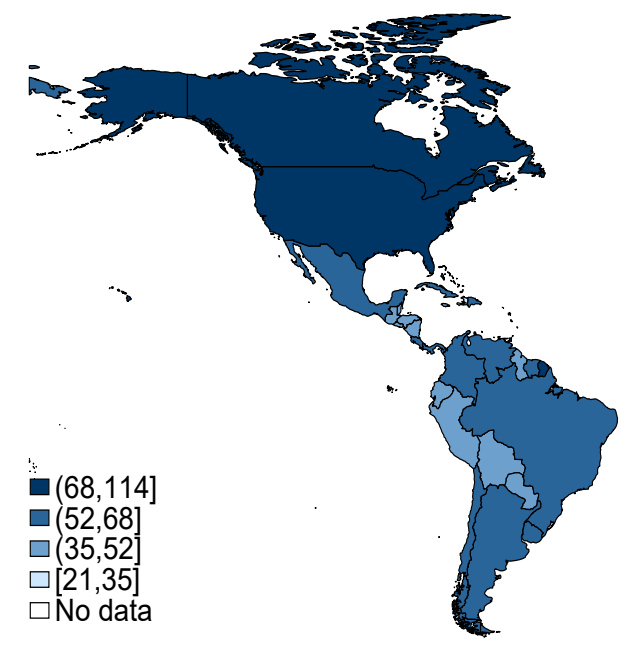

(b) India

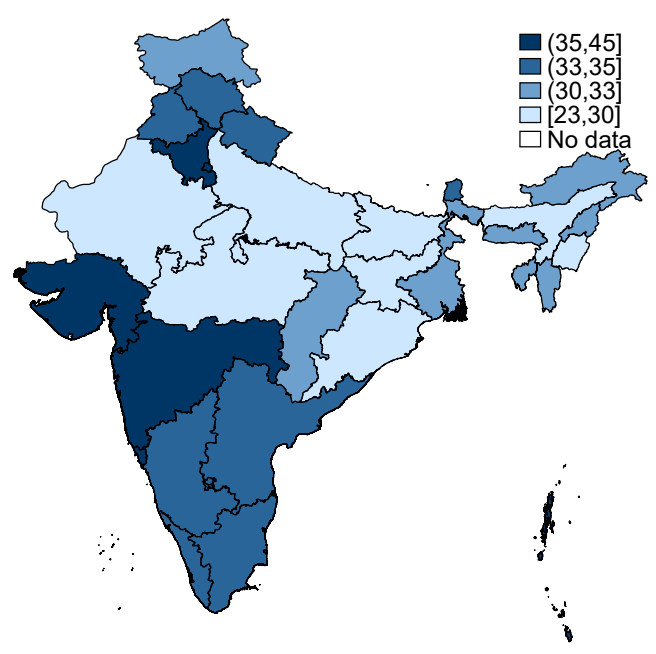

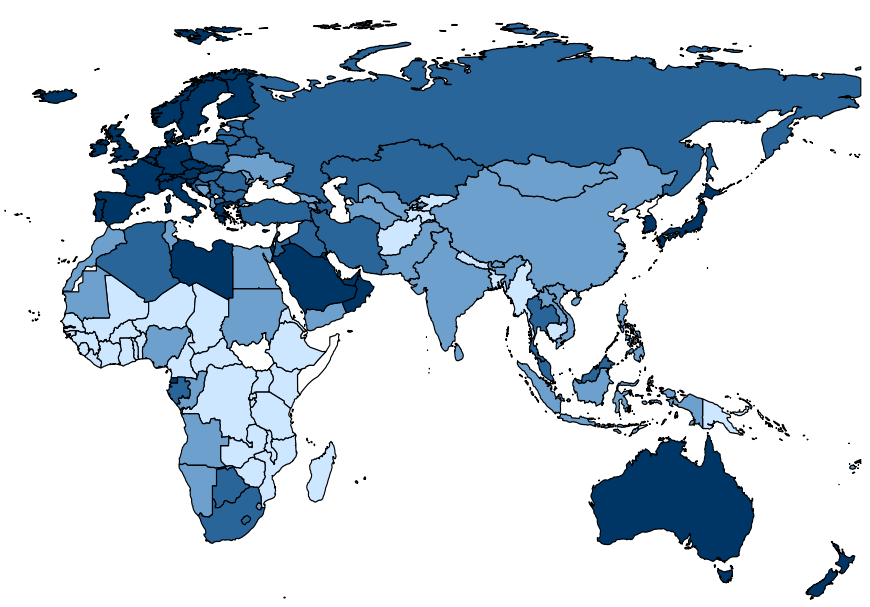

(c) Tanzania

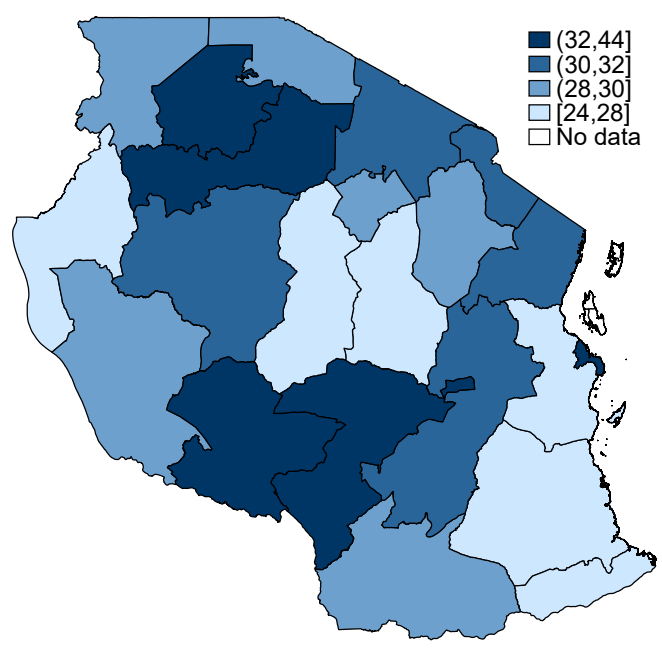

Note. Monthly household willingness to pay for private water sources (in 2008 USD calculated at purchasing power parity) is estimated by repeating the analysis in column (1) of Table 4. Household income is imputed from national/regional per capita income by assuming that the average household consists of six members, while PRIVTAP is set equal to 1. National income data are obtained from the World Bank (2016). Subnational income data for India are obtained from the World Bank (2013), and for Tanzania from its National Bureau of Statistics (2014). Maps are not to scale. Subnational maps reflect jurisdictional boundaries from 2008. 
sion model require several adjustments. First, to approximate costs for only improving drinking water services (not sanitation), we multiply the ratio of (1) the population without access to drinking water by (2) the combined population without access to improved water or sanitation. Country-level coverage estimates for 2000 were taken from the World Health Organization and United Nations Children's Fund Joint Monitoring Programme for Water Supply and Sanitation (WHO/UNICEF, 2010). Second, to estimate per capita costs averaged over the non-covered population rather than the total population, we divided by the percent of the population without drinking water coverage. Third, we converted from annual to monthly costs by dividing by twelve and from 2000 USD to 2008 USD by multiplying by the CPI inflation factor (see Pattanayak et al., 2010). Fourth, we converted from per capita to per household values by multiplying by six (rough estimate of persons per household).

To estimate average per-household WTP for these interventions and regions, we again applied meta-regression model (6) from Table 4 using the following specifications:

- For the first intervention (improved drinking water) we set baseline water conditions at unimproved (BASELINE1 $=1$ ) and assumed an increase in access to public water sources (PRIVTAP $=0$ ).

- For the second intervention (piped water) we assumed an increase in access to private water connections (PRIVTAP = 1) from the same baseline (BASELINE1 = 1).

- For household income, we used 2000 GDP per capita in each region (converted to per household per month figures in 2008 USD).

- For URBAN, we used the percent of the region's total non-covered population in 2000 that lived in urban areas (WHO/UNICEF, 2010). ${ }^{12}$

- For the region, we set the corresponding dummy variable equal to 1.

- Finally, we set STUDYAGE = 9, PUBLISHED = 1, HHINCMISS = 0, and all other variables at their study sample means.

Table 6 reports the resulting benefit-cost comparisons for three regions included by Haller et al. (2007) with relatively low levels of drinking water coverage-Africa, Asia, and the high mortality stratum of the Americas (AMR-D). ${ }^{13}$ The estimated per-household

\footnotetext{
${ }^{12}$ To obtain the appropriate coefficient, we reran the regression in model (6) with URBAN instead of URBDUMMY.

${ }^{13}$ Asia includes Indonesia, Sri Lanka, Thailand, Bangladesh, Bhutan, Democratic People's Republic of Korea, India, Maldives, Myanmar, and Nepal. The Americas (high mortality stratum, AMR-D) include Bolivia, Ecuador, Guatemala, Haiti, Nicaragua, and Peru.
} 
Table 6: Benefit-cost comparison for improved drinking water services, USD per household per month

\begin{tabular}{ccccc}
\hline \multirow{2}{*}{ Region } & \multicolumn{2}{c}{$\begin{array}{c}\text { Improved water coverage (98\%) } \\
\text { BASELINE1 }=1, \text { PRIVTAP }=0\end{array}$} & \multicolumn{2}{c}{ Piped water supply (98\%) } \\
& WTP & Costs & WASELINE1 = 1, PRIVTAP =1 & Costs \\
\hline Africa & 10.17 & 2.03 & 26.32 & 9.87 \\
Asia & 9.74 & 2.68 & 25.20 & 12.61 \\
Americas & 18.81 & 3.10 & 48.69 & 13.45
\end{tabular}

$\overline{\text { Note. This table presents regional estimates of benefits and cost of enhancing access to improved drinking }}$ water services (in 2008 USD calculated at purchasing power parity).

benefits of providing 98 percent access to improved drinking water services are greater than the estimated costs in all three regions. The difference is greatest in the Americas, where the estimated benefits are over six times the magnitude of costs. In addition, estimated benefits of access to private water connections also exceed costs in all regions, despite a fourfold increase in the cost of increasing piped water access relative to simply increasing improved water coverage.

It should be noted that the WTP estimates reported in Table 6 may overstate the benefits of improving drinking water access because they are based on mean household income levels for each region. The average income level in the non-covered population is likely to be below this mean. This may be of particular concern to policy-makers looking to expand access to improved water sources for low-income households in remote, rural regions, where the ratio of benefits to costs is likely to be the lowest (Whittington and Pattanayak, 2015). That said, our calculations suggest that income levels would need to be substantially below the mean-for instance, more than ninety percent below the mean in the Africa region-before the estimated costs of improving water coverage exceed its benefits.

\section{Conclusion}

We use meta-analysis in this study to synthesize results from a worldwide sample of sixty stated preference (SP) studies estimating household willingness to pay (WTP) for improved access to or quality of drinking water services. Using $171 \mathrm{WTP}$ estimates drawn from these studies and applying regression analysis, we examine a range of potential factors that explain variation in WTP estimates. We find that households' WTP are sensitive to 
scope (i.e., the size of the change in drinking water services), average household income, and SP elicitation method. Critically, the influence of these factors follows theoretical predictions and intuition. We then demonstrate how these regression models can be used to predict household-level WTP for selected improvements in drinking water access and services. This use of the regression model provides a useful framework for estimating the benefits of policies that improve households' access to these services. For example, in selected regions with currently low levels of coverage, we find that WTP for improved drinking water access greatly exceeds the cost of provision. However, the models also suggest that if considerable income disparities exist, the perceived private benefits of interventions that enhance access to piped water services may fail to exceed their costs. In such settings, policy-makers looking to promote increases in piped water coverage on the basis of merit-good or equity arguments may need to rely on external sources of finance (such as international aid) to cover the gap between benefits and costs. As global leaders move forward with policies in line with the water and sanitation Sustainable Development Goals (SDGs), our meta-analysis and the resulting first-order estimates of benefits for improved water access illustrate how one might distinguish settings where local finance could be sufficient from those where external financial assistance will be vital.

\section{Acknowledgments}

This research was partially supported by the US Environmental Protection Agency under contract EP-W-07-069. We thank two anonymous reviewers for their helpful comments.

\section{References}

AgUilar, M. AND T. STERnER (1995): “Willingness to pay for improved communal water services," Environmental Economics Unit Working Paper, Department of Economics, Gothenburg University.

Akram, A. A. And S. M. Olmstead (2011): “The Value of Household Water Service Quality in Lahore, Pakistan," Environmental and Resource Economics, 49, 173-198.

AL-GHuraiz, Y. AND A. ENSHASSI (2005): “Ability and willingness to pay for water supply service in the Gaza Strip," Building and Environment, 40, 1093-1102. 
AltAF, M. A. (1994): “Household demand for improved water and sanitation in a large secondary city," Habitat International, 18, 45-55.

Altaf, M. A., H. JAMAL, AND D. Whittington (1992): “Willingness to pay for water in rural Punjab, Pakistan," Tech. rep., World Bank, Washington, DC, prepared for the UNDPWorld Bank Water and Sanitation Program, Water and Sanitation Division, Infrastructure and Urban Development Department.

AROUNA, A. AND S. DABBERT (2012): “Estimating rural households' willingness to pay for water supply improvements: a Benin case study using a semi-nonparametric bivariate probit approach," Water International, 37, 293-304.

Bergstrom, J. C. AND L. O. TAYLOR (2006): “Using meta-analysis for benefits transfer: Theory and practice," Ecological Economics, 60, 351-360.

BILGIC, A. (2010): "Measuring willingness to pay to improve municipal water in southeast Anatolia, Turkey," Water Resources Research, 46.

BoADU, F. O. (1992): “Contingent Valuation for Household Water in Rural Ghana," Journal of Agricultural Economics, 43, 458-465.

BOHM, R. A., T. J. EsSENBURG, AND W. F. FOX (1993): "Sustainability of potable water services in the Philippines," Water Resources Research, 29, 1955-1963.

Boyle, K. J., C. F. Parmeter, B. B. Boehlert, And R. W. Paterson (2013): “Due Diligence in Meta-analyses to Support Benefit Transfers," Environmental and Resource Economics, 55, 357-386.

Brander, L. M., R. J. G. M. Florax, AND J. E. VermaAt (2006): “The Empirics of Wetland Valuation: A Comprehensive Summary and a Meta-Analysis of the Literature," Environmental \& Resource Economics, 33, 223-250.

Briscoe, J., P. F. De CAstro, C. Griffin, J. North, And O. Olsen (1990): “Toward Equitable and Sustainable Rural Water Supplies: A Contingent Valuation Study in Brazil," The World Bank Economic Review, 4, 115-134.

CARSON, R. T. (2000): “Contingent Valuation: A User's Guide," Environmental Science E Technology, 34, 1413-1418.

Carson, R. T., N. E. Flores, AND N. F. Meade (2001): “Contingent Valuation: Controversies and Evidence," Environmental and Resource Economics, 19, 173-210.

CARson, R. T. AND J. J. LOUviere (2011): “A Common Nomenclature for Stated Preference Elicitation Approaches," Environmental and Resource Economics, 49, 539-559.

CASEY, J. F., J. R. KAHN, AND A. RivAs (2006): “Willingness to pay for improved water service in Manaus, Amazonas, Brazil," Ecological Economics, 58, 365-372. 
ChOe, K. And R. VARley (1997): “Conservation and pricing-does raising tariffs to an economic price for water make the people worse off," Prepared for the Best Management Practice for Water Conservation Workshop, South Africa.

ChOWdhury, N. T. (1999): "Willingness to pay for water in Dhaka slums: A Contingent Valuation Study," in The Economic Value of the Environment: Cases from South Asia, ed. by J. E. Hecht, Kathmandu, Nepal: IUCN.

Confalonieri, U., B. Menne, R. Akhtar, K. Ebi, M. Hauengue, R. Kovats, B. ReVICH, AND A. WOODWARD (2007): "Human health," in Climate Change 2007: Impacts, Adaptation and Vulnerability. Contribution of Working Group II to the Fourth Assessment Report of the Intergovernmental Panel on Climate Change, ed. by M. Parry, O. Canziani, J. Palutikof, P. van der Linden, and C. Hanson, Cambridge, UK: Cambridge University Press, 391-431.

DAvis, J. (2004): “Assessing Community Preferences for Development Projects: Are Willingness-to-Pay Studies Robust to Mode Effects?" World Development, 32, 655-672.

DE OCA, G. S. M. AND I. J. BATEMAN (2006): “Scope sensitivity in households' willingness to pay for maintained and improved water supplies in a developing world urban area: Investigating the influence of baseline supply quality and income distribution upon stated preferences in Mexico City," Water Resources Research, 42.

DEL SAZ-SAlaZAR, S., F. GONZÁLEZ-GómeZ, AND J. GuARdiola (2015): “Willingness to pay to improve urban water supply: the case of Sucre, Bolivia," Water Policy, 17, 112. DUAN, N. (1983): "Smearing Estimate: A Nonparametric Retransformation Method," Journal of the American Statistical Association, 78, 605-610.

DutTA, V. (2005): "Public Support for Water Supply Improvements: Empirical Evidence From Unplanned Settlements of Delhi, India," The Journal of Environment \& Development, 14, 439-462.

EFEndic, A., G. PUGH, AND N. AdNetT (2011): “Institutions and economic performance: A meta-regression analysis," European Journal of Political Economy, 27, 586-599.

EgZIABHER, K. AND B. AdNEW (2007): "Valuing Water Supply Service Improvements In Addis Ababa," Ethiopian Journal of Economics, 16.

FISSHA, M. (2006): "Household demand for improved water service in urban areas: the case of Addis Ababa, Ethiopia," Master's thesis, Addis Ababa University.

FujITA, Y., A. FUJII, S. FURUKAWA, AND T. OGAWA (2005): “Estimation of willingnessto-pay (WTP) for water and sanitation services through contingent valuation method (CVM): A case study in Iquitos City, The Republic of Peru," JBICI Review, 11, 59-87. 
Genius, M., E. Hatzaki, E. M. KouromichelaKi, G. Kouvakis, S. NiKiforaKi, AND K. P. TSAGARAKIS (2008): “Evaluating Consumers' Willingness to Pay for Improved Potable Water Quality and Quantity," Water Resour Manage, 22, 1825-1834.

GENIUS, M. AND K. P. TSAGARAKIS (2006): “Water shortages and implied water quality: A contingent valuation study," Water Resources Research, 42.

GoldBLATT, M. (1999): “Assessing the effective demand for improved water supplies in informal settlements: a willingness to pay survey in Vlakfontein and Finetown, Johannesburg," Geoforum, 30, 27-41.

GunATILAKE, H. AND M. TACHIIRI (2012): “Willingness to pay and inclusive tariff designs for improved water supply services in Khulna, Bangladesh," Asian Development Bank South Asia Working Paper Series.

Gunatilake, H., J.-C. Yang, S. K. PattanayaK, And K. A. Choe (2007): “Good practices for estimating reliable willingness-to-pay values in the water supply and sanitation sector," Tech. rep., Asian Development Bank, http:/ /hdl.handle.net/11540/2354.

Haines, A., R. Kovats, D. Campbell-Lendrum, and C. Corvalan (2006): "Climate change and human health: impacts, vulnerability, and mitigation," The Lancet, 367, 2101-2109.

Haller, L., G. Hutton, AND J. BARTRAm (2007): "Estimating the costs and health benefits of water and sanitation improvements at global level," Journal of Water and Health, 5, 467.

HoeHn, J. P. AND D. J. KRIEGER (2000): “An Economic Analysis of Water and Wastewater Investments in Cairo, Egypt," Evaluation Review, 24, 579-608.

Holmes, T. P. AND R. A. KRAMER (1995): “An Independent Sample Test of Yea-Saying and Starting Point Bias in Dichotomous-Choice Contingent Valuation," Journal of Environmental Economics and Management, 29, 121-132.

Hopkins, O. S., D. T. LAuRiA, AND A. KOlb (2004): “Demand-Based Planning of Rural Water Systems in Developing Countries," J. Water Resour. Plann. Manage., 130, 44-52.

HoRVÁTHOVÁ, E. (2010): “Does environmental performance affect financial performance? A meta-analysis," Ecological Economics, 70, 52-59.

Howard, G., K. Charles, K. Pond, A. Brookshaw, R. Hossain, And J. Bartram (2010): "Securing 2020 vision for 2030: climate change and ensuring resilience in water and sanitation services," Journal of Water and Climate Change, 01, 2.

Jeuland, M., J. Orgill, A. Shaheed, G. Revell, And J. Brown (2015): “A matter 
of good taste: investigating preferences for in-house water treatment in peri-urban communities in Cambodia," Envir. Dev. Econ., 21, 291-317.

KADISA, K. (2013): "Willingness to pay for improved water supply services in Shoshong, Phaleng ward, Botswana: application of Contingent Valuation Method (CVM)," Master's thesis, University of Zimbabwe.

Kaliba, A., D. Norman, AND Y.-M. Chang (2003): "Willingness to pay to improve domestic water supply in rural areas of Central Tanzania: Implications for policy," International Journal of Sustainable Development $\mathcal{E}$ World Ecology, 10, 119-132.

KANYOKA, P., S. FAROLFI, AND S. MORARDET (2008): “Households' preferences and willingness to pay for multiple use water services in rural areas of South Africa: an analysis based on choice modelling," Water SA, 34, 715 - 723.

KATUWAL, H. AND A. BOHARA (2007): “Coping with unreliable water supplies and willingness to pay for improved water supplies in Kathmandu," Presented at the Second Annual Himalayan Policy Research Conference, Nepal Study Center.

Lauria, D., J. DAVIS, AND E. MCClelland (1995): “Final Report on Households' Willingness to Pay for Improved Water Supply and Sanitation in Maturin, Venezuela," Tech. rep., CVM, Inc., Chapel Hill, NC.

MCPHAIL, A. A. (1993): "The "five percent rule" for improved water service: Can households afford more?" World Development, 21, 963-973.

(1994): "Why Don't Households Connect to the Piped Water System? Observations from Tunis, Tunisia," Land Economics, 70, 189.

NAM, P. AND T. SON (2005): "Households Demand for Improved Water Services in Ho Chi Minh City: A Comparison of Contingent Valuation and Choice Modelling Estimates," Tech. rep., Economy and Environment Program for Southeast Asia, Singapore.

National Bureau of Statistics (2014): "National Accounts of Tanzania Mainland," Retrieved from http://www.nbs.go.tz/nbstz/index. $\mathrm{php} /$ english/statistics-by-subject/national-accounts-statistics/ 340-national-accounts-of-tanzania-mainland-2001-2013.

Nelson, J. P. And P. E. Kennedy (2009): “The Use (and Abuse) of Meta-Analysis in Environmental and Natural Resource Economics: An Assessment," Environmental and Resource Economics, 42, 345-377.

PattanayaK, S. K., C. Poulos, J.-C. YANG, AND S. PAtil (2010): “How valuable are environmental health interventions? Evaluation of water and sanitation programmes in India," Bulletin of the World Health Organization, 88, 535-542. 
Pattanayak, S. K., J. M. Wing, B. M. Depro, G. L. Van Houtven, P. De Civita, D. M. STIEB, AND B. HubBELL (2002): "International health benefits transfer application tool: the use of PPP and inflation indices," Tech. rep., RTI International, Research Triangle Park, NC, prepared for the Economic Analysis and Evaluation Division, Health Canada. Pattanayak, S. K., J.-C. Yang, C. Agarwal, H. M. Gunatilake, H. M. S. J. H. BANDARA, AND T. RANASINGHE (2004): "Water, Sanitation, and Poverty in Southwest Sri Lanka," Tech. rep., RTI International, Research Triangle Park, NC, prepared for the World Bank.

Pattanayak, S. K., J.-C. Yang, D. Whittington, K. C. Bal Kumar, G. Subedi, Y. B. Gurung, K. P. Adhikari, D. V. Shakya, L. S. KunWar, and B. K. Mabuhang (2001): “Willingness to Pay for Improved Water Supply in Kathmandu Valley, Nepal," Tech. rep., RTI International, Research Triangle Park, NC, prepared for the World Bank. Perez-PinedA, F. AND C. Quintanilla-Armijo (2013): “Estimating willingness-topay and financial feasibility in small water projects in El Salvador," Journal of Business Research, 66, 1750-1758.

Peters, E. J. AND Z. Mohamed (2010): “Willingness to pay for water on the Guyana east coast," Proceedings of the ICE - Water Management, 163, 315-323.

Pinheiro, A. And D. Whittington (1995): “Introducing a Demand-Side Approach to Rural Water Investment in Mozambique: A Rapid Appraisal of Household Demand for Improved Water Services in Marracuene," Tech. rep., National Rural Water Program (PRONAR), Maputo, Mozambique.

REDDY, V. R. (1999): “Quenching the Thirst: The Cost of Water in Fragile Environments," Development and Change, 30, 79-113.

RosADO, M. (1998): “Willingness to pay for drinking water in urban areas of developing countries," 1998 Annual meeting, August 2-5, Salt Lake City, UT 20821, American Agricultural Economics Association (New Name 2008: Agricultural and Applied Economics Association).

SHAH, A. S. (2003): "Value of Improvements in Water Supply Reliability in Zanzibar Town," Master's thesis, Yale School of Forestry and Environmental Studies.

Singh, B., R. Ramasubban, R. Bhatia, J. Briscoe, C. C. Griffin, And C. Kim (1993): "Rural water supply in Kerala, India: How to emerge from a low-level equilibrium trap," Water Resources Research, 29, 1931-1942.

SMith, V. K. AND S. K. PATtAnAyAK (2002): “Is Meta-Analysis a Noah's Ark for NonMarket Valuation?" Environmental and Resource Economics, 22, 271-296. 
StAnley, T. AND S. B. JARrell (1998): “Gender Wage Discrimination Bias? A MetaRegression Analysis," The Journal of Human Resources, 33, 947.

StOVELAND, S. AND B. BASSEy (2000): "Status of water supply and sanitation in 37 small towns in Nigeria," Paper Presented at the Donor Conference in Abuja, February 2-4, 2000.

Tussupova, K., R. BERndtsson, T. BRAMryd, AND R. Beisenova (2015): “Investigating Willingness to Pay to Improve Water Supply Services: Application of Contingent Valuation Method," Water, 7, 3024-3039.

UKOLI-ONODIPE, G. O. (2003): “Designing optimal water supply systems for developing countries," Ph.D. thesis, The Ohio State University.

United Nations (2007): “Millenium Development Goals," Tech. rep., United Nations, New York.

- (2014): “Open Working Group proposal for Sustainable Development Goals," Tech. rep., United Nations, New York.

VAIDYA, C. (1996): “Demand and willingness to pay for urban water and sanitation services in Baroda," Journal of Indian Water Works Association, 28, 87-92.

VAn Houtven, G. L. (2008): "Methods for the Meta-Analysis of Willingness-to-Pay Data," PharmacoEconomics, 26, 901-910.

VAn Houtven, G. L., J. POWERS, And S. K. PAttanayaK (2007): “Valuing water quality improvements in the United States using meta-analysis: Is the glass half-full or halfempty for national policy analysis?" Resource and Energy Economics, 29, 206-228.

VÁSQUEZ, W. F. (2014): “Willingness to pay and willingness to work for improvements of municipal and community-managed water services," Water Resources Research, 50, 8002-8014.

VÁsqueZ, W. F. AND D. FRANCESCHI (2013): "System Reliability and Water Service Decentralization: Investigating Household Preferences in Nicaragua," Water Resour Manage, 27, 4913-4926.

VÁsqueZ, W. F., D. FRANCESCHI, AND G. T. V. HECKEN (2012): “Household preferences for municipal water services in Nicaragua," Envir. Dev. Econ., 17, 105-126.

VÁsquez, W. F., P. Mozumder, J. Hernández-ArCe, And R. P. Berrens (2009): "Willingness to pay for safe drinking water: Evidence from Parral, Mexico," Journal of Environmental Management, 90, 3391-3400.

VIRJEE, K. (2006): “The Willingness to Pay for Changes in Water, Wastewater and Electricity 
Services in Trinidad and Tobago," Working Paper, Department of Civil Engineering, McGill University.

WANG, H., J. XIE, AND H. LI (2010): “Water pricing with household surveys: A study of acceptability and willingness to pay in Chongqing, China," China Economic Review, 21, 136-149.

WAsike, W. S. K. And N. Hanley (1998): “The Pricing of Domestic Water Services in Developing Countries: A Contingent Valuation Application to Kenya," International Journal of Water Resources Development, 14, 41-54.

Whitehead, J. C., S. K. Pattanayak, G. L. Van Houtven, And B. R. Gelso (2008):

"Combining Revealed and Stated Preference Data to Estimate the Nonmarket Value of Ecological Services: An Assessment of the State of the Science," Journal of Economic Surveys, 22, 872-908.

Whittington, D., J. Briscoe, X. MU, And W. BArron (1990a): “Estimating the Willingness to Pay for Water Services in Developing Countries: A Case Study of the Use of Contingent Valuation Surveys in Southern Haiti," Economic Development and Cultural Change, 38, 293-311.

WhitTington, D., D. T. LAURIA, AND X. MU (1991): “A study of water vending and willingness to pay for water in Onitsha, Nigeria," World Development, 19, 179-198.

Whittington, D., D. T. Lauria, A. M. Wright, K. Choe, J. Hughes, And V. Swarna (1992): "Household demand for improved sanitation services; a case study of Kumasi, Ghana," Tech. rep., World Bank, Washington, DC, prepared for the UNDP-World Bank Water and Sanitation Program, Water and Sanitation Division, Infrastructure and Urban Development Department.

Whittington, D., M. R. Mujwahuzi, G. McMahon, and K. Choe (1989): “Willingness to pay for water in Newala district, Tanzania: strategies for cost recovery," Tech. Rep. WASH Field Report No. 246, USAID, Washington, DC, prepared for the USAID Mission to Tanzania and UNICEF/Tanzania WASH Activity No. 445.

Whittington, D., A. Okorafor, A. OkOre, And A. McPhail (1990b): “Strategy for cost recovery in the rural water sector: A case study of Nsukka District, Anambra State, Nigeria," Water Resources Research, 26, 1899-1913.

Whittington, D. AND S. K. PATTANAYAK (2015): “Water and sanitation economics: reflections on application to developing economies," in Handbook of Water Economics, ed. by A. Dinar and K. Schwabe, Edward Elgar Publishing, chap. 24, 469-499. 
WHO/UNICEF (2010): "Progress on Sanitation and Drinking-water: 2010 Update," Tech. rep., WHO/UNICEF Joint Monitoring Programme for Water Supply and Sanitation.

- (2015): "Progress on Sanitation and Drinking Water: 2015 Update and MDG Assessment," Tech. rep., WHO/UNICEF Joint Monitoring Programme for Water Supply and Sanitation.

WidiYATI, N. (2011): "Willingness to Pay to Avoid the Cost of Intermittent Water Supply: A case study of Bandung, Indonesia," Master's thesis, University of Gothenburg.

WORLD BANK (2013): "India - Country partnership strategy for the period FY13-FY17," Retrieved from http://data.worldbank.org/data-catalog/india-cps.

- (2016): “World Development Indicators 2016," Retrieved from http://hdl . handle . net/10986/23969.

World Health ORGanization (2014): “Global Health Estimates 2000-2012,” Retrieved from http://www. who.int/healthinfo/global_burden_disease/estimates/en/.

Wright, S. G., D. Muralidharan, A. S. MaYer, AND W. S. BrefFle (2014): "Willingness to pay for improved water supplies in rural Ugandan villages," Journal of Water, Sanitation and Hygiene for Development, 4, 490.

YANG, J.-C., S. K. PATtANAyAK, F. R. JONSON, C. MANSField, C. VAn DEN BERG, AND K. JONES (2006): “Unpackaging Demand For Water Service Quality: Evidence From Conjoint Surveys In Sri Lanka," Tech. rep., The World Bank. 